\title{
Becker nevus syndrome
}

INSERM

\section{Source}

INSERM. (1999). Orphanet: an online rare disease and orphan drug data base. Becker nevus syndrome. ORPHA:64755

A rare, syndromic, benign, epidemal nevus syndrome characterized by the association of a Becker nevus (i.e. circumscribed, unilateral, irregularly shaped, hyperpigmented macules, with or without hypertrichosis and/or acneiform lesions, occuring predominantly on the anterior upper trunk or scapular region) with ipsilateral breast hypoplasia or other, typically hypoplastic, skeletal, cutaneous, and/or muscular defects, such as pectoralis major hypoplasia, supernumerary nipples, vertebral defects, scoliosis, limb asymmetry, odontomaxillary hypoplasia and lipoatrophy. 